\title{
LA ADMINISTRACIÓN PÚBLICA ANTE LA PRIMACÍA Y EFECTIVIDAD DEL DERECHO DE LA UNIÓN EUROPEA
}

\author{
Public administration applying the EU law's primacy and \\ effectiveness
}

\author{
Joaquín Sarrión Esteve \\ Investigador Ramón y Cajal \\ Universidad Nacional de Educación a Distancia (UNED) \\ jsarrion@der.uned.es
}

http://dx.doi.org/10.18543/ed-68(2)-2020pp231-255

Recibido: 16.11 .2020

Aceptado: 21.12.2020

\section{Resumen}

La primacía y efectividad del Derecho de la Unión Europea se proyecta también sobre la Administración Pública y sobre sus actos. Esto obliga a la Administración, como sucede con el juez nacional, a aplicar el Derecho europeo de forma efectiva, lo que exige realizar una interpretación conforme del derecho interno y de la práctica administrativa.

Sin embargo, a diferencia del juez nacional, la Administración Pública carece de la guía interpretativa del Tribunal de Justicia. Esto hace muy necesario tener en consideración la doctrina de este tribunal sobre la primacía y efectividad del Derecho europeo y su proyección sobre los actos administrativos, donde si bien la seguridad jurídica protege como regla general a los actos administrativos firmes, en algunos casos se deriva una facultad o una obligación de revisión de actos administrativos firmes.

El presente trabajo tiene como propósito realizar un análisis actualizado de la jurisprudencia del Tribunal de Justicia sobre la aplicación de la primacía y efectividad del Derecho de la Unión sobre los actos administrativos. 


\section{Palabras clave}

Administración Pública, seguridad jurídica, autonomía procedimental, primacía, efectividad del derecho de la UE

\section{Abstract}

The European Union law's primacy and effectiveness applies to Public Administration and its decisions. Therefore, Public Administration, as happens with a national judge, must apply EU law effectively, which a consistent interpretation of internal law and administrative practice.

However, unlike a national judge, Public Administration lacks the interpretative guide of the Court of Justice through the prejudicial question. Because of this, it is very important to consider the Court of Justice's doctrine on primacy and its projection on administrative decisions. As legal certainty principle protects in general final administrative acts, in some cases, there is a power or an obligation to review final administrative decisions.

The aim of this work is to carry out an updated analysis of the jurisprudence of the Court of Justice on the application of EU law primacy and effectiveness over administrative acts.

\section{Keywords}

Public Administration, legal certainty, procedural autonomy, primacy, EU law effectiveness 
SUMARIO: I. MOTIVACIÓN. II. SOBRE LA PRIMACÍA Y EFECTIVIDAD DEL DERECHO DE LA UNIÓN EUROPEA Y SU PROYECCIÓN SOBRE LA ADMINISTRACIÓN PÚBLICA. III. EL PRINCIPIO DE SEGURIDAD JURÍDICA Y LOS LÍMITES DE LA PRIMACÍA Y EFECTIVIDAD. IV. CONSIDERACIONES FINALES. V. REFERENCIAS BIBLIOGRÁFICAS.

\section{MOTIVACIÓN ${ }^{1}$}

El Derecho de la Unión Europea que, como se ha dicho con agudeza, «penetra día a día en todos los sectores jurídicos» (Chaves 2020, 119), necesita de una serie de principios jurídicos ${ }^{2}$, como son los principios de autonomía, efecto directo y primacía (Van Gend \& Loos, y Costa, 1964) ${ }^{3}$, así como el de interpretación conforme (Marleasing, 1990) ${ }^{4}$, en especial los dos últimos, primacía e interpretación conforme para dotar de efectividad al ordenamiento jurídico europeo ${ }^{5}$ y los derechos que confiere.

Estos principios al proyectarse sobre el ordenamiento jurídico español, rigiendo las relaciones entre ordenamientos, extienden su radio de influencia también sobre la Administración Pública, desde un punto de vista subjetivo, y sobre sus actos, desde un punto de vista objetivo. Esto obliga a la Administración, como sucede con el juez nacional, a aplicar el Derecho europeo de forma efectiva, lo que exige realizar una interpretación conforme del derecho interno y de la práctica administrativa.

${ }^{1}$ Agradecimientos. El autor agradece el apoyo de la Ayuda del Programa «Ramón y Cajal «(RYC) 2015 (RYC-2015-188821), financiado por el Ministerio de Ciencia e Innovación a través de la Agencia Estatal de Investigación (EAI), y cofinanciado por el Fondo Social Europeo.

2 Algunos autores consideran que estamos ante la proclamación, con autoridad, de principios calificados como constitucionales (De Vergottini 2010, 124).

3 Sentencias del Tribunal de Justicia de 5 de febrero, Van Gend \&Loos, 26/62, EU:C:1963:1, y de 15 de julio de 1964, Costa, 6/64, EU:C:1964:66.

${ }^{4}$ Sentencia de 13 de diciembre de 1990, Marleasing, 106/89, EU:C:1990:395.

5 El antiguo Derecho comunitario, hoy ya Derecho de la Unión Europea, aunque por comodidad y para facilitar la frescura de la lectura utilicemos indistintamente también las expresiones de Derecho comunitario e incluso de Derecho europeo, se basa en una doctrina ordinamental, al menos nominalmente. Sin lugar a dudas, la teoría del ordenamiento jurídico de Santi Romano es útil -por el institucionalismo y el pluralismo- para poder explicar el orden jurídico europeo, y sus relaciones con los ordenamientos jurídicos de los respectivos Estados miembros de la Unión, pero habría que analizar en profundidad si la concepción del Derecho comunitario, tal y como desarrolla en la práctica jurídica es ordinamental o más bien normativa, a pesar de las palabras que se suelen utilizar, lo que excedería por completo el propósito de este escrito. Sobre la tesis de Santi Romano, véase Romano (2013); Martín-Retortillo (1962); y Fontanelli (2018). 
Sin embargo, a diferencia del juez nacional, la Administración Pública carece de la guía interpretativa del Tribunal de Justicia. Esto hace muy necesario tener en consideración la doctrina sobre la primacía y efectividad del Derecho europeo y su proyección sobre los actos administrativos, donde si bien la seguridad jurídica protege como regla general a los actos administrativos firmes, en algunos casos se deriva una facultad o una obligación de revisión de actos administrativos firmes.

El presente trabajo tiene como propósito realizar un análisis actualizado de la jurisprudencia del Tribunal de Justicia sobre la aplicación de la primacía y efectividad del Derecho de la Unión sobre los actos administrativos y, por tanto, se centra en la perspectiva del Derecho europeo, sin perjuicio de que se hagan algunos comentarios complementarios o marginales desde la perspectiva del Derecho interno.

\section{SOBRE LA PRIMACÍA Y EFECTIVIDAD DEL DERECHO DE LA UNIÓN EUROPEA Y SU PROYECCIÓN SOBRE LA ADMINISTRACIÓN PÚBLICA}

El principio de primacía es de una gran importancia, pues sirve como criterio de resolución de los eventuales conflictos que puedan surgir entre las disposiciones que integran el ordenamiento jurídico europeo y las normas nacionales o internas de los Estados miembros, el principio de interpretación conforme sirve en una etapa previa para evitar un aparente conflicto que es solucionable vía interpretativa ${ }^{6}$.

Estos principios rigen la aplicación administrativa, a nivel nacional, del Derecho europeo, formando parte, junto a otros importantes principios de su régimen, de lo que se ha denominado derecho administrativo europeo (Fuentetaja Pastor 2017, 617) como podrían ser los principios de autonomía institucional y procedimental ${ }^{7}$, equivalencia y efectividad ${ }^{8}$, que el Tribunal de Justicia ha

${ }^{6}$ Aunque se suele diferenciar entre conflictos directos (cuando dos normas o disposiciones, una interna y otra europea, rigen un mismo asunto sin poder ser aplicadas de forma simultánea), e indirectos (cuando la norma o disposición europea y la nacional se aplican en diferentes niveles o áreas, por ejemplo esto ocurre cuando la norma europea rige el contenido sustantivo, pero el procedimiento de su aplicación es regido por la norma interna), para las colisiones y aproximarse a la jurisprudencia del Tribunal de Justicia al respecto, vamos a tratar de realizar una aproximación más general sin entrar en esta distinción, que suele, al final, dejar de lado los conflictos indirectos, muy frecuentes dada la autonomía institucional y procedimental de los Estados miembros. Sobre la distinción, véase Verhoeven (2009, 67; y 2011, 46)

7 Véase al respecto Sentencias del Tribunal de Justicia (ambas) de 16 de diciembre de 1976, Rewe, 33/76, EU:C:1976:188; y Comet, 45/76, EU:C:1976:191.

8 Sentencia del Tribunal de Justicia de 13 de marzo de 2007, Unibet, 432/05, EU:C:2007:163. 
venido delimitando de una forma casuística, lo que hace complejo elaborar una teoría sobra la validez de los actos administrativos internos en relación con el Derecho europeo, como destaca Fuentetaja (2017); que, no nos engañemos, formaría parte de la problemática más amplia sobre la articulación entre el ordenamiento jurídico europeo, de carácter autónomo, que se integra en el ordenamiento jurídico de cada uno de los Estados miembros, y por lo que aquí interesa, por tanto, en el ordenamiento jurídico español ${ }^{9}$.

Como es sabido, en principio, y salvo una concreta regulación europea, corresponde a los Estados miembros, conforme al principio de autonomía institucional y procedimental, regular los procedimientos que van a permitir la aplicación y efectividad del Derecho comunitario. Se suele hablar tanto de autonomía institucional, procedimental, como también procesal, pues su proyección se extiende también a los procesos judiciales.

Para ello, los Estados miembros deben, siguiendo el principio de cooperación leal (art. 4.3 del Tratado de la Unión Europea) adoptar todas las medidas que sean apropiadas para asegurar el cumplimiento de las obligaciones derivadas de los Tratados o bien resultantes de los actos de las instituciones europeas, absteniéndose de toda medida que pueda poner en peligro que la Unión consiga sus objetivos. Esto implica, por un lado, obligaciones para el legislador a la hora de regular el procedimiento, pero también supone, por el otro lado, facultades y obligaciones para el propio operador jurídico a nivel interno, y por tanto también para la Administración, que deberá proporcionar y garantizar una tutela adecuada de los derechos derivados del ordenamiento europeo, condicionando así el principio de autonomía procedimental (Sarrión Esteve 2020, 126).

Al fin y al cabo, el Derecho europeo necesita de la Administración Pública de los Estados miembros para su implementación a nivel interno de los Estados, o, dicho en otras palabras, la Administración Pública no dejaría de estar europeizada, o ser Administración Europea, aunque sea con esa doble función de aplicar derecho interno y Derecho europeo, lo que se ha venido a denominar el rol del «dédoublement fontionnel» de las autoridades administrativas nacionales (Le Barbier-Le Bris 2006, 427); aunque es más preciso decir que en

${ }^{9}$ Sobre la articulación entre el ordenamiento jurídico europeo y los respectivos ordenamientos jurídicos nacionales, con sus respectivas reglas, hay diversas teorías dogmáticas que tratan de explicar sus relaciones, a través de diversas técnicas y reglas jurídicas, que se construyen a través del estudio no sólo de las propias normas fundamentales de los distintos ordenamientos, sino también atendiendo a la jurisprudencia del Tribunal de Justicia, y de los tribunales constitucionales o supremos con función constitucional de los Estados, y que desde un prisma pluralista, federalista o soberanista, teorizan sobre la mejor manera de definir y precisar las relaciones entre distintos centros de poder y legitimación que coexisten e interactúan. Sobre estos problemas de articulación y teorías, véase Requejo Pagés (1995), MaccorMick (1999), Martín-Retortillo Baquer (2004), Muñoz Machado (2015), Fabbrini (2015), y Bobić (2017). 
realidad la Administración lo que debe hacer es aplicar un ordenamiento jurídico complejo integrado por normas de origen interno como externo.

Ahora bien, no se puede obviar otra circunstancia importante y es que este principio de cooperación leal debe ser leído en el sentido de que debe haber una cooperación mutua y sincera ${ }^{10}$, por tanto, que se proyectaría de un modo bidireccional.

Se suele decir, no obstante, que la remisión del Derecho europeo al interno no es incondicionada (Núñez Lozano 2017, 575), y que este principio está funcionalizado por el propio Derecho europeo, y puede ser objeto de precisión y delimitación por parte del Tribunal de Justicia precisamente para garantizar el llamado «efecto útil» del mismo (Galetta 2010, 122) o, en otras palabras, estaríamos ante una instrumentalización que no haría posible una elección libre, o autónoma estatal sino orientada (Arzoz Santisteban 2014, 197).

De esta manera el procedimiento, así como la regulación del mismo, deben posibilitar la garantía de los derechos derivados del ordenamiento europeo, para que este sea efecto; y la jurisprudencia del Tribunal de Justicia, cuando resuelve un caso a través del principio de autonomía procedimental, lo condiciona, como resume muy bien Unibet (2007), a los principios de equivalencia (el tratamiento no debe ser menos favorable que el de derechos nacionales similares) y de efectividad (no debe hacer imposible en la práctica o excesivamente difícil el ejercicio de los derechos conferidos a nivel europeo $)^{11}$.

Ahora bien, como los procedimientos en los que se aplica el Derecho de la Unión están regulados por el Derecho interno, y guiados por la práctica administrativa y judicial, es posible que en ocasiones se produzcan situaciones de conflicto. Evidentemente, el operador jurídico, la Administración en este caso, debe tratar de aplicar el derecho interno, así como la jurisprudencia y práctica administrativa de conformidad con lo previsto en el Derecho europeo, dándole efectividad según el principio de interpretación conforme; pero esto no siempre es posible, y puede producirse un conflicto en el que haya que dar, o no prevalencia al Derecho europeo.

Siguiendo a Sarmiento $(2016,272 \text {, y } 314)^{12}$, podemos decir que la primacía del derecho de la UE se manifiesta en dos vertientes: una normativa (conflicto abstracto), y otra aplicativa (conflicto concreto), ésta última se produce cuando en un caso concreto hay que elegir entre la aplicación del Derecho europeo y la

${ }_{10}$ Entre los Estados miembros y las institucionales de Unión Europea, cubriendo todas las áreas, con una aplicación horizontal entre los Estados miembros y las propias instituciones, y vertical entre los Estados miembros y la Unión Europea. Véase Tavares Lanceiro $(2018,73)$

11 Sentencia Unibet, ya citada.

12 Todo esto sin perjuicio de que el Estado mantenga la obligación de proceder a la modificación, anulación o derogación de la norma nacional incompatible, es decir, a su expulsión en definitiva del ordenamiento jurídico, véase Alonso García (2014a,92). 
norma nacional, y el operador jurídico, sea un juez o, por lo que ahora interesa, también una Administración ${ }^{13}$, porque una vez determinado que no es posible la interpretación conforme (que sería obligada si es posible) y tratándose de la aplicación de una disposición europea con efecto directo, debe proceder a inaplicar (desplazar) la disposición nacional, y ello con independencia de su naturaleza ${ }^{14} \mathrm{y}$ de su carácter temporal, anterior o posterior, respecto a la disposición europea ${ }^{15}$. Si esta disposición europea no gozara de efecto directo, y la interpretación conforme de la norma nacional no es posible, entonces la Administración aplicaría la norma de derecho interno, y el Derecho de la UE no será efectivo; quedando la puerta abierta a que el interesado afectado solicite la responsabilidad patrimonial del Estado por infracción del Derecho de la Unión ${ }^{16}$. Y todo ello sin perjuicio de que el Estado mantenga la obligación de proceder a la modificación, anulación o derogación de la norma nacional incompatible, es decir, a su expulsión en definitiva del ordenamiento jurídico ${ }^{17}$.

Por supuesto, es posible que la aplicación administrativa nacional del Derecho europeo sea contraria al mismo, bien porque se desconoce o aplica de forma incorrecta la disposición comunitaria, tal y como es interpretada por el Tribunal de Justicia, o porque existiendo un conflicto con una disposición nacional no se resuelve correctamente el $\mathrm{mismo}^{18}$. Y es que, a la postre, la

13 Véase Sentencia del Tribunal de Justicia de 22 de junio de 1989, Fratelli Costanzo, 103/88, EU:C:1989:256, apartado 32. Abarcando tanto las disposiciones administrativas de carácter general como las resoluciones administrativas individuales y concretas, véase Sentencia del Tribunal de Justicia de, 29 de abril de 1999, Ciola, 224/1997, EU:C:1999:212, apartado 32 .

${ }^{14}$ Por tanto, también respecto a normas constitucionales, véase Sentencia del Tribunal de Justicia de 17 de diciembre de 1970, Internationale Handelsgesellschaft, 11/70, EU:C:1970:114; y Sentencia del Tribunal de Justicia de 26 de febrero de 2013, Melloni, 399/11, EU:C:2013:107.

15 No estando el juez nacional obligado a esperar la modificación, derogación o anulación de la disposición nacional, ya sea por procedimientos legislativos o judiciales. Véase Sentencia del Tribunal de Justicia de 9 de marzo de 1978, Simmenthal, 106/77, EU:C:1978:49, apartado 24.

${ }^{16}$ Así, la responsabilidad patrimonial del Estado sería una cláusula de cierre del sistema para reparar a quienes puedan verse perjudicados por actos administrativos contrarios al Derecho europeo. Véase De los Mozos y Touya $(2017,690)$.

17 Véase Alonso García (2014a, 92).

18 Evidentemente, un eventual conflicto entre un acto administrativo interno y una disposición comunitaria puede ser directo cuando es el acto administrativo en sí mismo el que vulnera o priva de eficacia a la disposición comunitaria, o puede ser indirecto cuando es la norma interna que aplica el acto administrativo la que vulnera la disposición comunitaria, véase Fuentetaja (2017: 618); pero, como veremos más adelante, un eventual conflicto indirecto debería corregirse a través de la inaplicación de la disposición nacional cuando se den los requisitos exigidos por la jurisprudencia del Tribunal de Justicia. 
obligación de aplicar el derecho de conformidad con la doctrina que fije el Tribunal de Justicia abarca incluso aquellas relaciones jurídicas nacidas o constituidas con antelación a la propia sentencia ${ }^{19}$, pues tiene efectos ex tunc.

En cualquier caso, como hemos dicho, e indica acertadamente Fuentetaja, es problemático formular una teoría o doctrina general por la casuística y el propio carácter evolutivo de la jurisprudencia, lo que siempre hace necesario una revisión actualizada de la misma, para tratar de extraer algunas reglas siempre sometidas a la propia evolución de la jurisprudencia del Tribunal ${ }^{20}$. Este trabajo se limita precisamente a analizar esta doctrina y sus consecuencias para la aplicación del derecho por parte de la Administración, garantizando la efectividad de los derechos conferidos por el Derecho de la Unión a nivel interno y por tanto respecto del acto administrativo nacional ${ }^{21}$, es decir, tiene como preocupación, siguiendo la sugestiva expresión de Cobreros Mendazona, «la primacía administrativa del Derecho de la Unión Europea» $(2015,172)$; dejamos fuera del mismo, por tanto, el estudio del acto administrativo europeo ${ }^{22}$.

Para eso es preciso analizar, en primer lugar, aunque sea de forma breve, el alcance de la doctrina del Tribunal de Justicia sobre el alcance de la primacía y la efectividad en del Derecho de la Unión, en particular en lo que sea aplicable a los actos administrativos ${ }^{23}$.

19 Sentencia del Tribunal de Justicia de 27 de marzo de 1980, Denkavit, 61/79, EU:C:1980:100, apartado 16.

${ }^{20}$ Fuentetaja (2017,618-619). Como indica este autor a falta de una regulación precisa o una codificación del derecho administrativo europeo o, mejor dicho, un derecho de la Administración europeo, este se ha desarrollado jurisprudencialmente por el Tribunal de Justicia.

${ }^{21}$ El Tribunal de Justica debe quedar para resolver las dudas que se puedan plantear respecto al alcance de esta efectividad en relación con el derecho interno, o si se prefiere, debe quedar para resolver las dudas de interpretación sobre las disposiciones comunitarias y su relación con las disposiciones internas, e incluso con los actos administrativos internos; pero no podemos obviar que es que debe garantizar la efectividad del Derecho europeo es el Estado, y por tanto, tanto la Administración nacional como, en su caso, el juez nacional.

${ }^{22}$ Sobre este, como parte del derecho de la administración europea, véase Fuentetaja (2017, 619-623).

${ }^{23}$ Aquí, quizá, conviene hacer una precisión. Utilizo la expresión primacía y efectividad porque la doctrina del Tribunal de Justicia no se limita siempre a hablar de primacía. Ciertamente hay diversas líneas jurisprudenciales importantes, y el tratamiento de las relaciones entre el ordenamiento europeo y los ordenamientos nacionales por parte del Tribunal de Justicia es muy casuística, esto hace que en algunas ocasiones se utilice de forma muy clara el principio de primacía para garantizar la efectividad, pero en otras ocasiones, en particular cuando está en juego el principio de autonomía institucional y procedimental, el Tribunal de Justicia suele utilizar la doctrina sobre los principios de equivalencia y efectividad, por ello nos parece más preciso utilizar la expresión más completa de la primacía y efectividad. De esta forma hacemos referencia a las diferentes líneas jurisprudenciales y argumentos que puede utilizar la doctrina jurisprudencial europea para lograr el efecto útil del Derecho de la Unión. 
En la conocida sentencia Simmenthal, tan pronto como ya en 1978, el Tribunal de Justicia ya tuvo oportunidad de asentar que el principio de primacía conlleva que el Derecho comunitario con efecto directo hace inaplicable de pleno derecho cualquier disposición contraria, y ello es compatible con el principio de cooperación leal para que los Estados miembros proporcionen la protección jurídica efectiva de los derechos derivados del ordenamiento europeo, siendo incompatible toda disposición o práctica, legislativa, administrativa o judicial, que redujera la eficacia del ordenamiento europeo ${ }^{24}$; al final, por tanto, estamos hablando de una vinculación general a todas las autoridades nacionales, que incluye a las Administraciones Públicas como se manifiesta en Fratelli Costanzo (1989) ${ }^{25}$, que en realidad no dejaría de ser una extensión de la doctrina Simmenthal.

Aunque en sentencias anteriores el Tribunal de Justicia ya se había pronunciado sobre la obligación de las Administraciones Públicas de garantizar la efectividad del Derecho comunitario, incluso inaplicando una ley interna ${ }^{26}$; es verdad que hasta ese momento el razonamiento derivaba de la existencia de una norma interna declarada contraria al Derecho comunitario tras una declaración de incumplimiento por parte del Tribunal de Justicia, de forma que se había constatado la incompatibilidad de la norma interna con el Derecho europeo, por lo que lo novedoso y más relevante en Fratelli Costanzo, es que no hay necesidad de una previa declaración de incumplimiento por parte del Tribunal de Justicia (Cobreros Mendazona 2015, 174-176); de forma que las Administraciones Públicas estarían vinculadas y obligadas a garantizar la efectividad de las disposiciones de Derecho comunitario con efecto directo, es decir, si las obligaciones derivadas o, desde la perspectiva de la otra cara de la moneda, los derechos conferidos son claros y precisos.

En Costanzo, la disyuntiva era si la Administración estaba facultada o incluso obligada a aplicar una directiva comunitaria que tuviera efecto directo, alegada por el interesado, inaplicando una norma interna. En las conclusiones, el Abogado General sostenía que la Administración estaría facultada para ello, pero sólo obligada si existía un previo pronunciamiento judicial que precisara y aclarara el efecto directo de la directiva, basándose en que la Administración carecía de la herramienta -podríamos añadir hermenéutica- de la cuestión prejudicial ${ }^{27}$.

${ }^{24}$ Sentencia del Tribunal de Justicia de 9 de marzo de 1978, Simmenthal, 106/77, EU:C:1978:49, apartados 17-23.

25 Sentencia Fratelli Costanzo, ya citada, apartado 30.

26 Así, desde la Sentencia del Tribunal de Justicia de 13 de julio de 1972, Comisión c. Italia, 48/71, EU:C:1972:65, apartados 6-7; también en la Sentencia de 19 de enero de 1993, Comisión c. Italia, 101/91, EU:C:1993:16, apartado 24.

27 Conclusiones del Abogado General Otto Lenz, presentadas el 25 de abril de 1989, Fratelli Costanzo, 103/88, EU:C:1989:166, apartados 35 y ss. 
Ciertamente, a diferencia del juez nacional, la Administración tiene el problema de que no está facultada para plantear una cuestión prejudicial ${ }^{28}$, tampoco puede adoptar medidas provisionales respetando los requisitos que exige el propio Tribunal de Justicia, y el estatuto de estas autoridades o entidades nacionales, como regla general, no garantiza el mismo grado de independencia del que gozan los órganos jurisdiccionales nacionales, ni existe certeza de que apliquen el principio de contradicción que preside el debate judicial ${ }^{29}$, de ahí que sea más necesario si cabe la disposición de reglas claras de conflicto para cuando corresponde a la Administración Pública y las entidades del sector público aplicar el Derecho europeo, y darle efectividad.

Por ello, se podría sostener, de forma razonable, en la línea argumental planteada en las conclusiones de Fratelli Costanzo, que sólo cuando el asunto está aclarado, la Administración está obligada a inaplicar una norma nacional, mientras que si no es así, el asunto debería derivarse al juez nacional que tiene la herramienta de la cuestión prejudicial ${ }^{30}$.

Sin embargo el Tribunal de Justicia parece más beligerante en la tutela de la efectividad del Derecho comunitario en esta sentencia. Aquí, el Tribunal de Justicia razona que cuando una disposición de una directiva comunitaria tiene, desde el punto de vista de su contenido efecto directo (no está sujeta a condición alguna y es lo suficientemente precisa), los particulares la pueden invocar directamente, no sólo ante órganos jurisdiccionales ${ }^{31}$, sino ante cualquier organismo o entidad sometidos a la autoridad o control de un Estado

${ }^{28}$ Pues la Administración carece de la guía interpretativa del Tribuna de Justicia a través de la cuestión prejudicial, véase Alonso García (2014a, 326), o Strozzi, y Mastroianni $(2016,641)$.

${ }_{29}$ Sentencia del Tribunal de Justicia de, ABNA y otros, asuntos acumulados 453/03, 11/04, 12/04 y 194/04, EU:C:2005:741, apartados 108-109.

${ }^{30}$ Cobreros Mendazona $(2015,179)$, así, la Administración podría inaplicar una norma que ha sido declarada incompatible con el Derecho comunitario, porque habría un acto aclarado, aplicando la conocida doctrina CILFIT, Sentencia del Tribunal de Justicia de 6 de octubre de 1982, CILFIT, 283/81, EU:C:1982:335; pero si la cuestión no está clara, deberían ser el juez nacional quien tuviera que resolver el asunto. Este planteamiento lo encontramos también en las Conclusiones del Abogado General Ruiz-Jarabo en Unwealtanwalt von Kärnten, véase Conclusiones del Abogado General Dámaso Ruiz-Jarabo Colomer, presentadas el 25 de junio de 2009, Umweltanwalt von Kärnten, 205/08, EU:C:2009:397 apartados 51 y 52, que plantea que la tensión del conflicto normativo se resolvería si la obligación de inaplicar disposiciones internas se reservara a quien tiene la facultad de plantear una cuestión prejudicial, y por tanto a la Administración Pública únicamente cuando ejerce una función jurisdiccional que lo permita, recojo aquí la cita de Cobreros Mendazona (2015:182 y 189).

${ }^{31}$ Recuerda, en este sentido, la jurisprudencia sobre el efecto directo de las directivas, que cuando se produce las hace susceptibles de invocación por los particulares ante los órganos jurisdiccionales. Véase Fratelli Costanzo, apartado 29, donde cita las Sentencias 
miembro, y por tanto también ante la Administración Pública, incluyendo una administración local como era en este caso $^{32}$.

Esta doctrina se va confirmar posteriormente en diversas sentencias como Kampleman (1997) ${ }^{33}$, Ciola (1999) ${ }^{34}$, Larsy (2001) ${ }^{35}$, Jiménez Melgar $(2001)^{36}$, CIF $(2003)^{37}$, Petersen $(2010)^{38}$, Fuß $(2010)^{39}$, Gabeiro $(2010)^{40}$,

de 19 de enero de 1982, Becker, 8/81, EU:C:1982:7, y 26 de febrero de 1986, Marshall, 152/84, EU:C:1986:84.

32 Véase Fratelli Costanzo, ya citada, apartados 30-32. Considera Cobreros Mendazona que el Tribunal de Justica no muestra ningún titubeo al respecto, es muy claro, y esa obligación de inaplicación de las disposiciones nacionales se produciría aunque el asunto no se haya aclarado por una previa sentencia judicial $(2015,180)$.

33 Sentencia del Tribunal de Justicia de 4 de diciembre de 1997, Kampelmann y otros, asuntos acumulados 253 a 258/96, EU:C:1997:585, apartado 47.

${ }^{34}$ Sentencia Ciola, antes citada, apartados 25 y ss. Es verdad que en este caso la particularidad es que lo que debe inaplicar la Administración no es una norma jurídica sino un acto administrativo que sería incompatible con el Derecho comunitario, y en particular con el principio de la libre prestación de servicios, pero esto era consecuencia de la propia proyección de la primacía no sólo sobre normas legislativas, sino también sobre actos, tal y como manifiesta el Tribunal en Rewe, sentencia ya citada, apartado 43 .

35 Sentencia del Tribunal de Justicia de 28 de junio de 2001, Larsy, 118/00, EU:C:2001:368, apartados 51 y 52. Este caso es destacable, por un lado, porque la administración afectada es la de la seguridad social, pero también, por otro lado, porque la vulneración del Derecho comunitario del acto comunitario se desprendería de una interpretación errónea de una disposición comunitaria, existiendo una previa sentencia anterior del Tribunal de Justicia.

36 Sentencia del Tribunal de Justicia de 4 de octubre de 2001, Jiménez Melgar, 438/99, apartado 32 .

37 Sentencia del Tribunal de Justicia de 9 de septiembre de 2003, CIF, 198/01, EU:C:2003:430, en este caso respecto de una autoridad de la competencia, apartados 4950.

38 Sentencia del Tribunal de Justicia de 12 de enero de 2010, Petersen, 341/08, EU:C:2010:4, apartado 80. En este interesante caso, el conflicto deriva de una disposición nacional que establecía el límite de edad para ejercer como dentista concertado en los 68 años, fundamentada en la protección de la salud de los pacientes y que implicó una resolución de cese de la habilitación legal que fue objeto de recurso judicial, en cuyo proceso se plantea la cuestión prejudicial que el Tribunal de Justicia resuelve en el sentido de declarar la incompatibilidad, y en el apartado indicado la obligación de la autoridad nacional administrativa de no aplicar dicha disposición.

39 Sentencia del Tribunal de Justicia de 14 de octubre de 2010, Fuß, 243/09, EU:C:2010:609, apartados 61-63, donde declara que la obligación se extiende a todas las autoridades descentralizadas, como los Länder, las ciudades o los municipios.

40 Sentencia del Tribunal de Justicia de 22 de diciembre de 2010, Gaviero Gaviero y Iglesias Torres, asuntos acumulados 444/09 y 456/09, EU:C:2010:819, apartados 72 y 73. Se trata de un asunto que entra dentro de la saga iniciada por la sentencia Del Cerro Alonso (Sentencia del Tribunal de Justicia de 13 de septiembre de 2007, Del Cerro Alonso, 307/05, EU:C:2007:509) respecto al principio de no discriminación de los funcionarios 
Rosado Santana $(2011)^{41}$, Amia (2012) ${ }^{42}$, ANAFE (2012) $)^{43}$, entre otras ${ }^{44}$, hasta las más recientes, como Farrel (2017) ${ }^{45}$, y An Garda Siochána $(2018)^{46}$. Vamos a detenernos en estas últimas.

Antes, debemos considerar que ya en Marshall (1986) ${ }^{47}$, con antelación a la sentencia Costanzo, el Tribunal ya había tenido oportunidad de extender la vinculación del Derecho comunitario a todas las entidades del Estado, incluso cuando actúa como empresario y no ejerce potestades públicas.

interinos por causa de la relación laboral por tiempo determinado, y su derecho al cobro de los complementos salariales de antigüedad, el Tribunal tiene la oportunidad de constar que la obligación de los Estados miembros de alcanzar los resultados previstos en las directivas, así como de adoptar todas las medidas, tanto generales como particulares, apropiadas para asegurar sus obligaciones, se imponen a todas las autoridades nacionales, también en su condición de empleador público, si bien en el caso de que no sea posible por su parte una interpretación y aplicación de la normativa interna conforme a las exigencias comunitarias, estarían obligados, tanto los órganos judiciales como la Administración a aplicar íntegramente la normativa de la Unión y tutelar los derechos conferidos por la misma.

${ }^{41}$ Sentencia del Tribunal de Justicia de 8 de septiembre de 2011, Rosado Santana, 177/10, EU:C:2011:557, apartado 53. En este caso se trataba de una convocatoria de función pública que incumplía lo previsto en el Acuerdo marco sobre relaciones laborales de duración determinada y a los contratos celebrados por órganos de la Administración y entidades del sector público, cuya cláusula 4, con efecto directo, establecía el principio de no discriminación; al no valorar el periodo de trabajo como funcionario interino.

42 Sentencia del Tribunal de Justicia de 24 de mayo de 2012, Amia, 97/11, EU:C:2012:306, apartados 28 y 39, donde refiere la vinculación de las autoridades administrativas descentralizadas como la Provincia Regional de Palermo, a las disposiciones de Derecho comunitario con efecto directo, a las que se imponen.

${ }^{43}$ Sentencia del Tribunal de Justicia de 14 de junio de 2012, ANAFE, 606/10, EU:C:2012:348, apartado 75.

${ }^{44}$ Selección realizada mediante búsqueda de jurisprudencia del autor, así como atendiendo a la selección realizada por Alonso García (2014b, 326), Cobreros Mendazona (2015, 180-181); y Arena $(2019,305)$,

45 Sentencia del Tribunal de Justicia de 10 de octubre de 2017, Farrel, 413/15, EU:C:2017:745,

46 Sentencia del Tribunal de Justicia de 4 de diciembre de 2018, An Garda Síochána, 378/17, EU:C:2018:979, apartados 38 y siguientes.

${ }^{47}$ Sentencia Marshall, ya citada. Cuando se invocó por una particular el principio de no discriminación frente a los servicios de salud británicos, y el Reino Unido alegó que actuaba en calidad de empresario, el Tribunal consideró que la invocación del Derecho comunitario cabía frente al Estado, tanto si actuaba en calidad de autoridad pública como de otro tipo. A partir de aquí, señala Mangas Martín, el Tribunal de Justicia amplia la noción de Estado «como una mancha de aceite», y si bien reconoce que la finalidad es proteger los derechos de los particulares, considera que puede generar dudas e incertidumbre, tanto para los particulares como para los propios órganos públicos (Mangas Martín 1993, 72). 
En Farrel se constata que la vinculación no se extiende únicamente a la Administración Pública, en un sentido estricto, sino también a organismos o entidades sometidos a la autoridad o control del Estado o que dispongan de facultades de carácter exorbitante en relación con las que se derivan de las normas aplicables a las relaciones entre particulares, es decir, desde el punto de vista del Tribunal de Justicia estos organismos o entidades no son particulares, y ello con independencia de que se sometan a derecho público o privado; y por tanto, desde el punto de vista del Derecho comunitario deben asimilarse al Estado.

Esto puede deberse a que se trate de personas jurídicas de derecho público, o bien porque estén sometidas a la autoridad o control de una autoridad pública, o porque esta autoridad les haya encomendado el ejercicio de una misión de interés público con facultades exorbitantes. Así sucedía en este caso con un organismo como el MIBI irlandés, que tiene atribuida la indemnización de víctimas de circulación de automóviles, cuando el vehículo no ha sido identificado o cuando no se haya satisfecho el correspondiente seguro obligatorio de responsabilidad civil, dado que el legislador irlandés obliga a todas las compañías de seguros de automóvil en Irlanda a asociarse a este organismo, confiríendole por ello facultades exorbitantes, lo que hace que un particular pueda invocar ante la misma un acto europeo con efecto directo, aunque esta entidad estuviera sujeta, en el ordenamiento jurídico interno, al derecho privado ${ }^{48}$.

An Garda Síochána es una sentencia derivada de una inadmisión en el proceso selectivo de policía por edad, lo interesante es el problema competencial derivado, y que se plantea en relación con la atribución por parte del legislador (irlandés, de nuevo) a un órgano nacional, como la Comisión de Relaciones Laborales, la función de garantizar la aplicación del derecho de la UE en un ámbito específico, como es el del principio de no discriminación en materia de empleo y ocupación, pero al que no se le atribuye competencia para dejar inaplicada una norma nacional contraria al Derecho europeo, que estaría reservada a un tribunal judicial.

Entiende el Tribunal de Justicia que si bien en base al principio de autonomía procedimental los Estados miembros pueden reservar la competencia para controlar la validez de las normas internas incompatibles con el Derecho europeo, la obligación de dar efectividad al mismo es general para todos los órganos nacionales, no sólo los órganos judiciales sino también los organismos administrativos, por lo que hay obligación de proporcionar efectividad ${ }^{49}$.

Hay que advertir, además, que esta proyección es amplísima, puesto que también se extiende respecto de las entidades estatales aunque Estado aunque

\footnotetext{
48 Sentencia Farrel, ya citada, apartados 34-40.

49 Sentencia An Garda Síochána, ya citada, apartados 43 y ss.
} 
actúe Además de esta cuestión respecto a la naturaleza de las entidades obligadas a dar efectividad a las disposiciones europeas, esta proyección del principio de primacía se extiende no sólo respecto a disposiciones administrativas de carácter general, sino también a las individuales y concretas, es decir, a los propios actos administrativos que sean contrarios al Derecho comunitario, incluso firmes, puesto que no perderían su naturaleza de disposición interna, como se refleja ya desde Ciola $(1999)^{50}$.

Ahora bien, esta doctrina, nacida en Fratelli Costanzo, y así planteada de forma generalizada y maximalista, también llamada como la «obligación Costanzo» (Costanzo obligation) ${ }^{51}$ aunque proporciona cierta seguridad respecto a la efectividad que puede atribuir al Derecho comunitario, lo hace, aparentemente, a costa de la seguridad jurídica de los propios ordenamientos jurídicos internos en los que se integra el Derecho comunitario, y es que podría, incluso, afectar a la firmeza de los actos y resoluciones administrativas y, por qué no decirlo, también incluso herir de muerte los efectos de cosa juzgada de las resoluciones judiciales, que no dejan de ser actos internos.

Por ello, no es de extrañar que aunque han existido opiniones favorables $^{52}$, la doctrina Costanzo haya sido el foco de duras críticas y reacciones, utilizando, entre otros argumentos que, por un lado, parece exigir que la Administración exceda los poderes que tiene atribuidos en el derecho

50 Sentencia Ciola, antes citada, apartados 25 y ss.

51 Véase Verhoeven (2009; y 2011, 117 y ss.).

52 Trayter Jiménez (1991, 254-259), autor que si bien ve como favorable la sentencia, se cuestiona cómo va a poder la Administración aplicarla; Doménech Pascual (2011, 99 y ss.) para el que de hecho, no solo las Administraciones Públicas pueden y deben inaplicar, por su propia autoridad, las normas legales y reglamentarias inválidas, cuando son contrarias al Derecho comunitario, sino también por otras razones, cuando son, por ejemplo, inconstitucionales $(2911,106)$; así como también Cobreros Mendazona (2015: 202-203) si bien esta autora propone una serie de garantías distinguiendo los casos en los que la incompatibilidad se haya declarado judicialmente de forma previa (por el propio Tribunal de Justicia vía recurso por incumplimiento, o cuestión prejudicial; o a nivel interno por el Tribunal Supremo o por un Tribunal Superior de Justicia en el caso de leyes autonómicas, que hayan determinado la inaplicación de la ley interna); y 2) en el resto de casos considera que la Administración únicamente podrá inaplicar una disposición interna cuando tenga un convencimiento pleno y objetivo de la antinomia y lo justifique de forma motivada. Aunque llega también a proponer de forma sugerente, para salvar las eventuales suspicacias, aplicar salvando las distancias, la doctrina del acto claro, es decir, que la Administración Pública podrá inaplicar una disposición interna tanto cuando sea clara la incompatibilidad porque ha quedado aclarada judicialmente como cuando sea tan evidente que no quede lugar a duda razonable porque se trataría de una convicción que se impondría a las Administraciones Púbicas de otros Estados, así como al propio Tribunal de Justicia; dejando abierta también la puerta a que el legislador regule el mecanismo. 
interno, afectando por tanto a la separación de poderes ${ }^{53}$, o al principio de legalidad ${ }^{54}$, o, que por otro lado, el Tribunal de Justicia no procede igual cuando se trata de suspender de forma cautelar la aplicación de un acto comunitario aunque su validez haya sido cuestionada ante el Tribunal de Justici $^{55}$. Incluso el Consejo de Estado, en su famoso Informe sobre la inserción del derecho europeo (2008), se hace eco de la doctrina Costanzo, y de los problemas de seguridad jurídica de la facultad de la Administración de inaplicar disposiciones internas contrarias al Derecho europeo ${ }^{56}$.

Aunque, en nuestra opinión, el cuestionamiento más razonable sigue siendo, como ya se apuntó en las propias conclusiones del Abogado General Otto Lenz en Fratelli Costanzo $0^{57}$, y hemos adelantado, que la Administración

${ }^{53}$ Véase De Witte $(2011,323$ y ss.)

${ }^{54}$ Véase Azpitarte Sánchez (2004, 87). Sobre las tensiones que plantea respecto del principio de legalidad en los ordenamientos nacionales de los Estados miembros de Alemania, Francia y Países Bajos véase Verhoeven (2009:71 y ss.; y 2011: 123-166).

${ }_{55}$ Como el Tribunal de Justicia tiene ocasión de precisar en $A B N A$. Véase Alonso García (2014b: 329).

${ }_{56}$ Véase Informe del Consejo de Estado sobre la inserción del Derecho Europeo en el Ordenamiento Español, 14 de febrero de 2008, disponible aquí: http://www.consejoestado.es/pdf/Europa.pdf, (240 y ss.), en el que el Consejo de Estado no solo se hace eco de la doctrina Costanzo, sino que preocupado por la inseguridad jurídica que puede producir la atribución a las Administraciones Públicas de la facultad de inaplicar disposiciones internas propone como una eventual solución de lege ferenda, la introducción de la potestad de la Administración para inaplicar el derecho interno incompatible con el Derecho comunitario, si bien condicionando dicha potestad a un previo dictamen favorable del Consejo de Estado u órgano consultivo equivalente de la Comunidad Autónoma, lo que implicaría por tanto, atribuir una potestad legal a la Administración de inaplicar una disposición interna, pero requiriendo para ello un dictamen preceptivo y vinculante del propio Consejo de Estado. introducir la obligación para las mismas de requerir un dictamen de carácter preceptivo y vinculante al Consejo de Estado. Esta propuesta, sin duda, interesante, tiene varios problemas, pero el principal es que en el hipotético caso de que el informe, de carácter vinculante, estableciera la compatibilidad, si aun así la Administración considerara que la disposición interna es incompatible con el Derecho comunitario, o peor aún, en el ínterin se dicta alguna sentencia del Tribunal de Justicia que pone de manifiesto esta incompatibilidad, desde la perspectiva del Derecho comunitario, la Administración seguiría obligada, por la doctrina Costanzo, a inaplicar la disposición interna incompatible, así como el propio dictamen del Consejo de Estado, que no deja de ser un acto interno. Posteriormente, emitirá otro informe en 2010 en el que propone de una forma más ambiciosa la aprobación de una ley que sistematice los mecanismos de garantía del cumplimiento del Derecho de la Unión, incluyendo los medios de prevención y reacción, así como el de responsabilidad, véase Informe del Consejo de Estado sobre las Garantías del Cumplimiento del Derecho Comunitario, 15 de diciembre de 2010, accesible aquí: http://www.consejo-estado.es/pdf/derecho\%20comunitario.pdf (309 y ss.). Y parece que finalmente algo se está trabajando para su articulación normativa,

${ }^{57}$ Conclusiones del Abogado General Otto Lenz, citadas. 
carece de un instrumento como la cuestión prejudicial, que sí pueden usar los jueces nacionales, para aclarar una eventual duda respecto del Derecho comunitario que está obligada a aplicar desplazando en caso de ser necesario una disposición interna. Esto, creo, es lo que puede ser más determinante en la posición que tiene la Administración a la hora de garantizar la efectividad del Derecho comunitario, pues no se plantea ningún problema desde la perspectiva de la sujeción al principio de legalidad (art. 103.1 CE), en la medida que la sujeción es en un sentido amplio lo es a la ley y al Derecho ${ }^{58}$, debiendo entender incluido en el Derecho, es decir, en nuestro ordenamiento jurídico, como orden o sistema jurídico complejo, el propio ordenamiento jurídico de la Unión, ex art. $93 \mathrm{CE}$.

El Tribunal Constitucional español sí parece admitir la doctrina Costanzo. Como es sabido, aunque el TC había venido configurando al Derecho comunitario como un derecho que carecía de rango constitucional, atribuyendo a los jueces ordinarios la aplicación del mismo ${ }^{59} \mathrm{y}$, por pura lógica, había considerado que un conflicto entre normas internas y disposiciones comunitarias no adquiere (por sí mismo, añadiríamos nosotros) relevancia constitucional ${ }^{60}$; la evolución de la doctrina del Tribunal Constitucional muestra una progresiva apertura hacia el Derecho europeo, tanto aceptando el principio de primacía

${ }^{58}$ En el mismo sentido, véase Cobreros Mendazona $(2015,201)$. En contra de esta posición, y como indica esta autora (pág. 197), el Tribunal Supremo parece no admitir la doctrina Costanzo cuando niega que la Administración pueda ejercer el juicio de prevalencia en el conflicto entre normas, que correspondería al juez, y no a la Administración, por su sujeción al imperio de la ley (art. 103.1 CE). Véase Sentencia del Tribunal Supremo, Sala de lo Contencioso, 3879/2012, de 23 de Mayo, rec. n. 7113/2010, fundamentos sexto y séptimo. Esta sentencia, sin duda es muy interesante, porque el se trata de un supuesto en el que la Administración revisa de oficio y declara la nulidad de una concesión que se había basado en una ley autonómica posteriormente declarada contraria al Derecho comunitario por el Tribunal de Justicia. Lo interesante es ver los dos planos, el Tribunal Supremo por un lado niega que en el momento en que se dictó la concesión la Administraición pudiera realizar el examen de prevalencia, tanto porque en ese momento no se había declarado el incumplimiento derivado de la ley autonómica incompatible con el Derecho comunitario, como también porque la Administración está sujeta a la ley; y por otro lado, el alto Tribunal español también niega que posteriormente la Administración pueda revisar de oficio y declarar la nulidad del acto para dar efectividad al Derecho europeo, puesto que no está previsto como causa de nulidad, y al hacerlo estaba aplicando un régimen de validez que no es aplicable a las relaciones derecho interno-DUE, ya que el conflicto es de prevalencia y de norma aplicable, no de validez, aunque hipotéticamente plantea la posibilidad de que podría haber resultado adecuado utilizar el mecanismo de la anulación, por vulneración del ordenamiento jurídico, al estar integrado el Derecho comunitario en el ordenamiento español, si bien lo plantea de forma hipotética.

59 STC 21/1991, de 31 de enero (Sala Primera).

${ }^{60}$ SSTC 252/1988, de 20 de diciembre (Pleno), y también en las SSTC 28/1991, de 14 de febrero (Pleno); 197/1996, de 28 de noviembre (Pleno). 
aunque no como principio de supremacía jerárquica, sino como exigencia existencial Derecho europeo que juega desde la perspectiva del principio de competencia y de la selección de la norma aplicable ${ }^{61}$; controlando la falta de planteamiento de una cuestión prejudicial ${ }^{62}$; e incluso planteando el propio TC una cuestión prejudicial ante el Tribunal de Justicia ${ }^{63}$. En este contexto, donde la sentencia del TC 145/2012, merece una especial atención, puesto que constata la vinculación de la Administración Pública al principio de primacía, con la consecuencia de la nulidad con eficacia ex tunc de una norma declarada por el Tribunal de Justicia como incompatible con el Derecho comunitario, aceptando además que la vinculación de la primacía opera para todos los órganos jurisdiccionales españoles, incluyendo el propio $\mathrm{TC}^{64}$.

En cualquier caso, es importante señalar también la eventual afectación de la seguridad jurídica por la doctrina Costanzo, principio que también goza

${ }^{61}$ Declaración del Tribunal Constitucional 1/2004, de 13 de diciembre (Pleno). Véase también, por todas, SSTC 26/2014, de 13 de febrero (Pleno), y 37/2019, de 26 de marzo (Pleno).

62 SSTC 58/2004, de 19 de abril (Sala Segunda), 194/2006, de 19 de junio (Sala Segunda), en ambas que, sin plantear una cuestión prejudicial, el tribunal había optado por inaplicar una ley interna vigente (en el primer caso una ley autonómica, y en el segundo una ley estatal), el TC otorga el amparo como consecuencia de la falta de planteamiento de una cuestión prejudicial, por vulneración del derecho a la tutela judicial efectiva y a un proceso con todas las garantías. Posteriormente, en la STC 78/2010, de 20 de octubre (Pleno), desestima el amparo, pues considera que el planteamiento de la cuestión prejudicial sólo resultará preciso, desde la perspectiva del art. $24 \mathrm{CE}$, cuando concurran los presupuestos fijados por el Derecho comunitario, cuestión que corresponde apreciar a los jueces y tribunales de la jurisdicción ordinaria (véase fundamento jurídico 2), y en este caso no podía entenderse procedente, dando por buena en este caso la inaplicación de una disposición autonómica interna por oposición al Derecho europeo; además se trata de una sentencia donde el TC parece asumir sin complejos la doctrina del acto aclarado y del acto claro del Tribunal de Justicia. No obstante, posteriormente hay algunas sentencias como las SSTC 27/2013, de 11 de febrero (Sala Primera), 212/2014, de 18 de diciembre (Pleno), y 99/2015, de 25 de mayo (Sala Primera), en las que las resoluciones judiciales que deciden aplicar una disposición interna sin plantear una cuestión prejudicial son dadas por buenas, al cumplir la exigencia de una suficiente exteriorización de los criterios jurídicos que las fundamentan, no tratándose de interpretaciones manifiestamente irrazonables de la legalidad ordinaria. Las dos primeras motivaron un voto particular de la Magistrada Adela Asúa que entendía que había un cambio de la doctrina del Tribunal desfigurando la doctrina del Tribunal de Justicia. El mantenimiento de la doctrina constitucional que ampara en los casos de inaplicación de una ley interna sin plantear una cuestión prejudicial, podría deducirse que la doctrina constitucional difiere en función de si la consecuencia de la falta de planteamiento de la cuestión prejudicial por el juez nacional es o no la inaplicación de una ley interna, véase, por todas, STC 37/2019, de 26 de marzo (Pleno).

${ }^{63}$ ATC 867/2011, de 9 de julio.

${ }^{64}$ STC 145/2012, de 2 de julio (Sala Primera), fundamento jurídico 7. 
de un gran valor y autoridad en el Derecho europeo, por lo que el Tribunal de Justicia matizó o precisó esta cuestión en otra línea jurisprudencial a veces obviada.

\section{III.EL PRINCIPIO DE SEGURIDAD JURÍDICA Y LOS LÍMITES DE LA PRIMACÍA Y EFECTIVIDAD}

Como hemos señalado en el apartado anterior, la doctrina desarrollada a partir de la sentencia Fratelli Costanzo atribuye una relevancia determinante al principio de primacía que se impone a la Administración Pública, así como también a cualquier entidad del sector público, o incluso del sector privado cuando ejerza funciones públicas. Además, desde el punto de vista del objeto, se proyecta sobre cualquier tipo de acto o resolución de estas entidades, y obliga a desplazar la aplicación de las normas o disposiciones nacionales en beneficio de las disposiciones comunitarias.

Pues bien, en lo que atañe a la vinculación de las Administraciones Públicas por el Derecho europeo, el Tribunal de Justicia tuvo oportunidad de ponderar la propia autoridad y la efectividad del mismo en el caso Kühne \& Heitz $(2004)^{65}$.

Aquí el Tribunal de Justicia tiene la oportunidad de afirmar la importancia del principio de seguridad jurídica, en relación con las resoluciones administrativas, afirmando que el Derecho comunitario no exige per se que un órgano administrativo esté obligado, en principio, a reconsiderar una resolución administrativa que hubiera adquirido firmeza, permitiendo por tanto una modulación del principio de primacía a través de la seguridad jurídica ${ }^{66}$, pero no de forma absoluta, como veremos.

Se trata también, quizá, como se ha dicho, de dar una respuesta al necesario equilibrio con la interpretación uniforme del derecho de la UE (Martinico 2013, 147), es decir, de ponderar. Ciertamente, la seguridad jurídica, a pesar de que es un concepto sujeto a evolución, no deja de ser un principio inherente del Estado de Derecho, y un principio constitucional de los Estados miembros de la Unión, así como un principio fundamental en el propio Derecho comunitario y en otros sistemas jurídicos transnacionales (Fenwick y Wrbka 2016,2) y, si bien como tal no está regulado de forma expresa en los Tratados, el propio Tribunal de Justicia lo ha configurado como un principio general -fundamental- del Derecho de la UE, como parte de su ambición

${ }^{65}$ Sentencia del Tribunal de Justicia de 13 de enero de 2004, Kühne \& Heitz, 453/00, EU:C:2004:17 apartado 24.

${ }_{66}$ Véase en el mismo sentido, entre otras, la Sentencias del Tribunal de Justicia de 3 de septiembre de 2009, Fallimento Olimpiclub, 2/08, EU:C:2009:506. 
para superar las limitaciones de los tratados, y determinación para ejercer el control del ejercicio del poder (Weatherill 2016, 233).

En este caso, Kühne \& Heitz era una empresa que había exportado trozos de aves de corral a países terceros durante el período 1986-1987, habiendo declarado ante las autoridades de aduanas en Países Bajos que estas exportaciones se incluirían en la subpartida arancelaria de muslos, contramuslos y trozos de otras aves de corral del Arancel Aduanero Común, por lo que obtuvo ciertas restituciones previstas para la promoción de estas exportaciones; pero las autoridades revisaron y modificaron la clasificación, requiriendo el reembolso económico. La empresa reclamó contra este requerimiento, y tras la desestimación administrativa contra la reclamación se apeló, si bien también este recurso fue desestimado por sentencia, sin que se solicitar por parte de la empresa el planteamiento de una cuestión prejudicial. Posteriormente, el Tribunal de Justicia dictó una sentencia en la que declaró que un muslo al que se mantiene unido un trozo de lomo debe calificarse como muslo si no le confiere un carácter esencial; tras la que la empresa solicitó en vía administrativa el pago de las restituciones que se habían reclamado reembolsar, pero se desestimó, decisión administrativa que se recurrió judicialmente, lo que conllevó al litigio principal del que deriva la cuestión prejudicial.

En esta cuestión prejudicial, el juez de instancia manifiesta que un órgano administrativo holandés tiene en principio la facultad de reconsiderar una resolución firme, que puede implicar la obligación de revocar la decisión, según las circunstancias. Sin embargo, se plantea también que la anulación de la decisión administrativa de no revisar tiene utilidad si el órgano administrativo no sólo tiene la facultad de reconsiderar su decisión, sino la obligación de reexaminarla si existía el derecho de restitución, y determinar su importe, por lo que se pregunta si a la luz del Derecho comunitario, y en particular del principio de cooperación leal se exige que un órgano administrativo reconsidere una resolución firme para garantizar la plena eficacia del Derecho UE, interpretándolo a la luz de una sentencia posterior a la resolución objeto de revisión ${ }^{67}$.

En la sentencia comunitaria podemos apreciar la ponderación que realiza el Tribunal de Justicia que, si bien tiene presente la importancia de la seguridad jurídica, y por tanto de la firmeza de una resolución administrativa, considera que esta protección no puede ser de carácter absoluto; razonando que el órgano administrativo estará obligado a examinar, de nuevo, una resolución administrativa firme, para tener en consideración una interpretación del Tribunal de Justicia sobre una disposición europea aunque sea posterior,

${ }^{67}$ Sentencia Kühne \& Heitz, antes citada, apartados 5-19. 
cuando se den las siguientes condiciones: a) dispone de esta facultad conforme al derecho interno; b) la resolución administrativa ha adquirido firmeza a raíz de una sentencia judicial; c) la sentencia judicial resuelve en última instancia basándose en una interpretación del derecho de la UE que a la luz de la jurisprudencia del Tribunal de Justicia posterior es errónea, y se ha adoptado sin someter cuestión prejudicial ante el mismo; y d) el interesado se dirige al órgano administrativo de forma inmediata después de tener conocimiento de la jurisprudencia del Tribunal de Justicia ${ }^{68}$.

Es interesante observar como una facultad prevista en el derecho interno se convierte, desde el punto de vista del Derecho europeo, en una obligación del órgano administrativo. Llama la atención, también, la rigidez de los otros requisitos: la firmeza debe derivar de una sentencia judicial, es decir, el interesado ha tenido que acudir a los tribunales; esta sentencia debe haberse basado en una interpretación errónea sin haber planteado una cuestión prejudicial, que se manifiesta en la jurisprudencia posterior del Tribunal de Justicia; y el interesado debe dirigirse de forma inmediata al órgano administrativo tras tener conocimiento de la jurisprudencia europea.

Cabe considerar que estamos ante unos requisitos claramente restrictivos y difíciles de cumplir (Chalmers, Davies, y Monti 2014, 95), y al estar fundados en el ordenamiento jurídico interno y corresponder a las autoridades nacionales la valoración de la situación concreta a la luz del mismo, puede tener repercusiones serias para los derechos de los individuos derivados del Derecho europeo, e incluso plantear dificultades en ciertos Estados miembros, con soluciones diversas (Groussot y Minssen 2007, 401), afectando en última instancia a una homogénea efectivad del Derecho UE.

Sin embargo, debemos valorar la doctrina Kühne \& Heitz en su justa medida, puesto que si no se condicionan a ciertos requisitos los supuestos en los que cabe una revisión administrativa firme, muy vinculados a la regulación interna, difícilmente se mantendría cierta autonomía institucional y procedimental, pues la primacía y efectividad no exigen, necesariamente, una total y completa uniformidad.

No obstante, sí consideramos necesaria una flexibilización de los requisitos que refuercen la efectividad del Derecho comunitario. Entendemos que se debería mantener la exigencia de que exista la facultad de revisión prevista en el ordenamiento interno ${ }^{69}$, pero los otros requisitos serían susceptibles de ser menos rígidos, pues se puede constatar la vulneración del Derecho

${ }^{68}$ Ibid., apartados 27 y 28.

69 Para aquellos supuestos en los que en el ordenamiento jurídico interno no exista facultad de revisión de decisiones administrativas firmes por parte de la propia Administración la vía para garantizar la efectividad pasará por el mecanismo de la responsabilidad patrimonial. 
comunitario derivada de una interpretación administrativa errónea, que adquiere firmeza, sin necesidad de que haya revisión judicial de la misma, y en caso de que la haya, sin que ésta sentencia necesariamente haya aplicado de forma errónea el Derecho europeo como se manifiesta de una decisión posterior del Tribunal de Justicia, pues puede producirse por desconocimiento indebido de jurisprudencia anterior del propio Tribunal de Justicia.

Esta doctrina iniciada en Kühne \& Heitz, y que complementa la obligación Costanzo, se confirma en diversas sentencias y se mantiene inalterada ${ }^{70}$. Es importante destacar, no obstante, algunas precisiones. Así, en la sentencia Kempter (2008), el Tribunal de Justicia concreta que no es necesario haber alegado o invocado el Derecho de la Unión en el marco del recurso judicial, así como que la revisión de la resolución administrativa firme no está sujeta, desde el punto de vista del Derecho comunitario, a un límite temporal determinado, si bien los Estados miembros sí pueden sujetarla a unos plazos razonables ${ }^{71}$; y en Byankov (2012) razona que las circunstancias particulares concurrentes en el caso pueden convertir la facultad de revisión en una obligación de revisión de la resolución administrativa firme para tener en consideración la interpretación posterior del Tribunal de Justicia, de forma que se garantiza así el equilibrio entre la seguridad jurídica y el principio de legalidad comunitario ${ }^{72}$.

Desde luego, si se cumplen las condiciones de la doctrina Kühne \& Heitz, la Administración estará obligada, para dar efectividad a una disposición del Derecho europeo, ya no a inaplicar una disposición interna, sino incluso a revisar una resolución o acto administrativo aún firme.

Fuera de estos supuestos, para resolver el problema y dar efectividad al Derecho europeo, encontramos el mecanismo de la responsabilidad del Estado miembro; o en su caso, si se trata de disposiciones o prácticas incompatibles, incluso el procedimiento por incumplimiento o procedimiento de infracción que podría iniciar la Comisión Europea, supuestos en los que parece que no hay una obligación de modificación de la decisión judicial más allá de la constatación del incumplimiento ${ }^{73}$.

${ }^{70}$ Véase Sentencias del Tribunal de Justicia de 28 de febrero de 2008, Kempter, 2/06, EU:C:2008:78, apartados 46 y 60; de 4 de octubre de 2012, Byankov, 249/11, EU:C:2012:608, apartado 77; de 20 de diciembre de 2017, Incyte, 492/16, EU:C:2017:995, apartados 46 y 47; de 16 de octubre de 2019, Glencore, 189/18, EU:C:2019:861, apartado 45; de 14 de mayo de 2020, FMS y otros, asuntos acumulados 924/19 PPU y 925/19 PPU, EU:C:2020:367, apartados 186 y 187.

71 Sentencia Kempter, ya citada, apartados 46 y 60.

72 Sentencia Byankov, citada, apartado 77

${ }^{73}$ Es verdad que respecto al procedimiento de incumplimiento, una eventual declaración por parte del Tribunal de Justicia se plantean dificultades, como señala Kremer, y hay discusión en la doctrina sobre la existencia de efectos ex nunc de la eventual sentencia y 
Lo que pasa es que la eventual responsabilidad por daños puede consolar en algunos casos al individuo cuyos derechos derivados del Derecho comunitario no se han hecho efectivos, pero puede no servir de mucho cuando se mantiene una discriminación o se impide la efectividad de los derechos que se pretendían, y tampoco parece que esperar que la Comisión Europea eventualmente inicie un procedimiento de incumplimiento pueda ser relevante para el individuo (Kornezov 2014, 810); pero son los límites que podemos encontrar a la propia efectividad del Derecho europeo y su primacía en aras de la seguridad jurídica.

\section{IV.CONSIDERACIONES FINALES}

La Administración Pública y las entidades del sector público están vinculadas por la primacía y efectividad del Derecho de la Unión Europea. Esto obliga a que el operador jurídico, también en el ámbito del procedimiento administrativo, aplique las disposiciones internas de conformidad con las disposiciones comunitarias, puesto que las normas del Derecho europeo se incorporan al ordenamiento jurídico (complejo, y multinivel) del Estado miembro y, por tanto, la sujeción a las mismas deriva también del principio de legalidad y sujeción al Derecho (art. $103 \mathrm{CE}$ ).

Para garantizar esta efectividad, cuando es aplicable una disposición comunitaria con efecto directo, el operador jurídico administrativo debe interpretar siempre las disposiciones internas de conformidad con la misma. Es verdad que la Administración Pública, a diferencia de un juez nacional, no tiene la facultad de plantear una cuestión prejudicial. Si no es posible la interpretación conforme, se produciría una colisión o conflicto que se debe resolver inaplicando la disposición interna, y resolviendo de conformidad con la disposición europea, puesto que rigen el principio de primacía, como se deriva de la doctrina del Tribunal de Justicia desarrollada a partir de la sentencia Fratelli Costanzo.

No obstante, hay límites a la primacía, puesto que como regla general la seguridad jurídica garantiza los efectos de la firmeza de las decisiones administrativas, a pesar de que se manifiesten contrarias al Derecho comunitario tras una sentencia del Tribunal de Justicia. Sin embargo, la primacía y efectividad del Derecho europeo pueden exigir también la revisión de una resolución o acto administrativo firme, si se cumplen las condiciones establecidas en la sentencia Kühne \& Heitz, es decir, si la Administración dispone de esta facultad conforme al derecho interno; la resolución administrativa ha

si genera o no una obligación de corregir la sentencia que ha motivado el incumplimiento, si bien parece la mayoría de autores entiende que no se daría esta obligación (Kremer, 2010: 200 y ss), opinión que comparto. 
adquirido firmeza a raíz de una sentencia judicial que ha resuelto en última instancia basándose en una interpretación del Derecho de la UE que a la luz de la jurisprudencia del Tribunal de Justicia posterior es errónea, y se ha adoptado sin someter cuestión prejudicial ante el mismo (a pesar de que el interesado no haya alegado el Derecho europeo en la instancia judicial, Kempter), y el interesado se dirige al órgano administrativo de forma inmediata después de tener conocimiento de la jurisprudencia del Tribunal de Justicia; ya que esta facultad, atendiendo a las circunstancias del caso puede convertirse en obligación (Byankov)

Si la disposición comunitaria no goza de efecto directo, o bien el conflicto no se resuelve en favor de la disposición europea, bien porque en sistema o el ordenamiento jurídico del Estado miembro no lo permite, ya sea por una interpretación errónea del Derecho de la UE, por una práctica incompatible con el mismo, o porque en caso de que lo que era necesario era la revisión de un acto firme y no existe esa posibilidad, la solución para dar efectividad al Derecho europeo pasa por el mecanismo de la responsabilidad patrimonial del Estado miembro, y en caso necesario del procedimiento de incumplimiento.

\section{REFERENCIAS BIBLIOGRÁFICAS}

Alonso García, Ricardo. 2014a. Las sentencias básicas del Tribunal de Justicia de

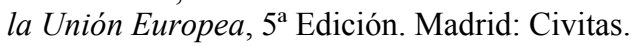

— 2014b. Sistema Jurídico de la Unión Europea, $4^{\mathrm{a}}$ edición, Madrid: Civitas.

Arena, Amedeo. 2019. "The Twin Doctrines of Primacy and Pre-emption», en Oxford Principles of European Union Law. Volume I: The European Union Legal Order, editado por Robert Schütze, y Takis Tridimas, 305-349. Oxford: Oxford University Press.

Arzoz SANTISTEBAN, Xabier. 2014. «La autonomía institucional y procedimental de los Estados miembros en la Unión Europea: Mito y Realidad», Revista de Administración Pública, $\mathrm{n}^{\circ}$ 191: 159-197.

AzPitarte SÁnChez, Miguel. 2004. «Las relaciones entre el derecho de la Unión y el Derecho del Estado a la luz de la Constitución Europea, Revista de Derecho Constitucional Europeo, $\mathrm{n}^{\circ} 1$.

Bobić, Ana. 2017. «Constitutional Pluralism Is Not Dead: An Analysis of Interactions Between Constitutional Courts of Member States and the European Court of Justice», German Law Journal, v. 18, nº 6: 1395-1428.

Chalmers, Damian, Davies, Gareth, y Monti, Giorgio. 2014. European Union Law: Text and Materials, $3^{\mathrm{a}}$ edición. Cambridge: Cambridge University Press.

Chaves, José Ramón. 2020. Derecho Administrativo Mínimo. Salamanca: Editorial Amarante.

Cobreros Mendazona, Edorta. 2015. «La aplicación del principio de primacía del Derecho de la Unión Europea por la Administración», Revista Vasca de Administración Pública, $\mathrm{n}^{\circ}$ 103: 171-207. 
De los Mozos y Touya, Juan Ignacio. 2017. «Efectos de la invalidez por infracción del derecho europeo». En El alcance de la invalidez de la actuación administrativa, 689-694. Madrid: INAP.

De Vergottini, Giuseppe. 2010. Más allá del diálogo entre tribunales. Madrid: Civitas.

De Witte, Bruno. 2011. «Direct Effect, Primacy, and the Nature of the EU Legal Order», en The Evolution of EU Law, ed. por Paul Craig, y Grainne de Búrca, 323-362. Oxford: Oxford University Press,

DoméNeCh PASCUAL, Gabriel. 2011. «La inaplicación administrativa de reglamentos ilegales y leyes inconstitucionales», Revista de Administración Pública, $\mathrm{n}^{\circ} 155$.

FABBRINI, Federico. 2015. Fundamental Rights in Europe, Oxford: Oxford University Press.

Fenwick, Mark y WrbKa, Stephan. 2016. «The Shifting Meaning of Legal Certainty», en Legal Certainty in a Contemporary Context editado por Mark Fenwick y Stephan Wrbka, 1-6. Singapur: Springer.

FonTANELli, Filippo. 2018. «Santi Romano and L'ordinamento giuridico: The Relevance of a Forgotten Masterpiece for Contemporary International, Transnational and Global Legal Relations», Transnational Legal Theory, v.11, n 2: 67-117.

Fuentetaja Pastor, José. 2017. «Invalidez y revisión de los actos administrativos contrarios al derecho europeo», El alcance de la invalidez de la actuación administrativa, 616-659. Madrid: INAP.

Galetta, Diana-Urania Galetta. 2010. Procedural Autonomy of EU Member States: Paradise Lost?, Verlag Berlin Heidelberg: Springer.

Groussot, Xavier y Minssen, Timon. 2007. «Res Judicata in the Court of Justice Case Law: Balancing Legal Certainty with Legality?». European Constitutional Law Review, $\mathrm{n}^{\circ}$ 3, 385-417.

Kornezov, Alexander. 2014. «Res Iudicata of National Judgements incompatible with EU Law: Time for a major rethink?». Common Market Law Review, v. 51, $\mathrm{n}^{\circ} 3,809-842$.

Le BARBIER-Le Bris, Muriel. 2006. «Les principes d'autonomie institutionnelle et procédurale et de cóoperation loyale. Les États Membres de l'Union Européenne: des États pas comme les autres», en Le droit et L'Union européenne en principes: liber amicorum en l'honneur de Jean Raux, 419-457. Rennes: Apogée.

MaccorMick, Neil. 1999. Questioning Sovereignty. Law, State and Nation in the European commonwealth. Oxford: Oxford University Press,

MAngas Martín, Araceli. 1993. «Las relaciones entre el Derecho comunitario y el Derecho interno en los estados miembros a la luz de la jurisprudencia del Tribunal de Justicia», en El Derecho comunitario y su aplicación judicial, dirigido por Gil Carlos Rodríguez Iglesias y Diego Liñán Nogueras, 55-96. Madrid: Consejo General del Poder Judicial, Universidad de Granada.

Martín-Retortillo, Sebastián. 1962. «La doctrina del ordenamiento jurídico de Santi Romano y algunas de sus aplicaciones en el campo del Derecho». Revista de Administración Pública, $\mathrm{n}^{\circ}$ 39: 39-78.

MARTíN-RETORTILlo BAQUER, Lorenzo. 2004. La interconexión de los ordenamientos jurídicos y el sistema de fuentes. Madrid: Civitas. 
Martinico, Giuseppe. 2013. The Tangled Complexity of the EU Constitutional Process. Londres y Nueva York: Routledge.

MuÑoz Machado, Santiago. 2015. «Los tres niveles de garantías de los derechos fundamentales en la Unión Europea: problemas de articulación», Revista de Derecho Comunitario Europeo, ${ }^{\circ}$ 50: 195-230.

NúÑEz LozAno, María Carmen. 2017. «La eficacia de las sentencias del Tribunal de Justicia de la Unión Europea sobre los actos nacionales». En El alcance de la invalidez de la actuación administrativa, págs. 549-613. Madrid: INAP.

ReQueJo PAGÉs, José Luis. 1995. Sistemas normativos, Constitución y Ordenamiento. La Constitución como norma sobre la aplicación de normas. Londres: McGraw Hill.

Romano, Santi. 2013. Ordenamiento Jurídico, editado por Lorenzo Martín-Retorti1lo. Madrid: Centro de Estudios Políticos y Constitucionales.

Sarmiento, Daniel. 2016. El Derecho de la Unión Europea. Madrid: Marcial Pons.

SARrión Esteve, Joaquín. 2020. «El Tribunal de Justicia de la Unión Europea y la protección del consumidor en la crisis financiera», Federalismi.it. Rivista di Diritto Pubblico Italiano, Comparato, Europeo, $\mathrm{n}^{\circ}$ 13: 118-131.

Strozzi, Girolamo, y Mastroianni, Roberto. 2016. Diritto dell'Unione Europea, $4^{\mathrm{a}}$ edición. Turín: Giappichelli.

TAVARES LANCEIRO, Rui. 2018. «The implementation of EU law by national administrations: Executive federalism and the principle of sincere cooperation», Perspetives on Federalism, v. 10, nº 1: 71-102.

TRAYTER JimÉNEZ, Joan Manuel. 1991. «El efecto directo de las directivas comunitarias: el papel de la Administración y de los jueces en su aplicación», Revista de Administración Pública, $\mathrm{n}^{\circ}$ 125: 227-280.

Verhoeven, Maartje. 2009. «The 'Costanzo obligation' of national administrative authorities in the light of the principle of legality: 'prodigy or problem child?», Croatian Yearbook of European Law \& Policy, v. 5, nº1: 65-93.

- 2011. The Costanzo Obligation: the obligations of national administrative authorities in the case of incompatibility between national law and European law. Cambridge: Intersentia.

WeAtherill, Stephen (2016), Law and Values in the European Union, Oxford: Oxford University Press. 


\title{
LA ADMINISTRACIÓN PÚBLICA ANTE LA PRIMACÍA Y EFECTIVIDAD DEL DERECHO DE LA UNIÓN EUROPEA
}

\author{
Public administration applying the EU law's primacy and \\ effectiveness
}

\author{
Joaquín Sarrión Esteve \\ Investigador Ramón y Cajal \\ Universidad Nacional de Educación a Distancia (UNED) \\ jsarrion@der.uned.es
}

http://dx.doi.org/10.18543/ed-68(2)-2020pp231-255

\section{Copyright}

Estudios de Deusto es una revista de acceso abierto, lo que significa que es de libre acceso en su integridad. Se permite su lectura, la búsqueda, descarga, distribución y reutilización legal en cualquier tipo de soporte sólo para fines no comerciales, sin la previa autorización del editor o el autor, siempre que la obra original sea debidamente citada y cualquier cambio en el original esté claramente indicado

Estudios de Deusto is an Open Access journal which means that it is free for full access, reading, search, download, distribution, and lawful reuse in any medium only for non-commercial purposes, without prior permission from the Publisher or the author; provided the original work is properly cited and any changes to the original are clearly indicated. 